\title{
Performance Analysis of Routing Protocols in MANET
}

\author{
Mohamed Otmani ${ }^{1}$, Dr. Abdellah Ezzati ${ }^{2}$ \\ ${ }^{1}$ (Department of Computer Science and Engineering/ University Hassan 1 Settat, Morocco) \\ ${ }_{2}^{2}$ (Department of Computer Science and Engineering/ University Hassan 1 Settat, Morocco)
}

\begin{abstract}
A Mobile Ad-hoc Network (MANET) consists of several mobile wireless nodes. It is infrastructureless, self organized and self configurable network in which the mobile nodes move arbitrarily. A routing protocol establishes correct and efficient route between mobile nodes and find the routes to facilitate communication within the network. Route should be discovered and maintained with minimum overhead and bandwidth consumption. Here topology based routing protocols, both proactive and reactive protocols have been considered for study. The performance of routing protocols (DSDV, AODV, OLSR, DSR, TORA, ZRP) is analyzed in terms of their packet delivery ratio, throughput, end-to-end delay, bandwidth, control overhead and energy consumption. We analyze the solution of routing in MANET and evaluate its performance using Network Simulator-2 (NS-2) under different network parameters.
\end{abstract}

Keywords: MANET, NS-2, Routing protocols, DSDV, AODV, OLSR, DSR, TORA, ZRP

\section{Introduction}

The A mobile ad hoc network (MANET) is a wireless communication network, consists of a number of mobile devices that come together to form a network as needed, without any support from any existing Internet infrastructure or any other kind of fixed stations. It is a self-configuring, infrastructure-less network of mobile devices. These devices are free to move independently in any direction and will be change its links to other devices frequently. In a dynamic environment, nodes are independent and they can move in any direction and thus mobility causes frequent change of network connectivity. Nodes in MANET can act as end points of data interchange as well as routers when the two end points are not in direct range of each other. In a decentralized network, a node is responsible to find the topology information and deliverance of data to the destination. The implementation of appropriate routing protocol is based on the nature of application. There are two classes of routing protocols in MANET - Proactive and Reactive protocols, and each constitute a set of protocols. Some of the routing protocols are proactive, reactive, hybrid protocols. Proactive routing is a table-driven routing, in which the nodes of network should maintain valid routes to all the destinations at all time. Reactive routing means on demand routing, in which the nodes of the network do not always maintain routing information.

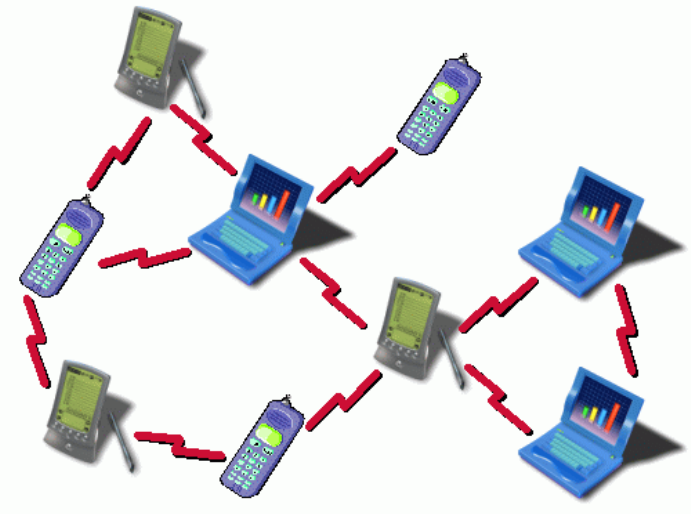

Fig.1: Example of MANET

A mobile ad hoc network (MANET) is a wireless communication network, that can operate without existing infrastructure and support mobile users. It falls under the general scope of multihop wireless networking. This networking paradigm originated from the needs in emergency operations, battlefield communications, search and rescue, and disaster relief operations. The most salient challenges in this area of research include end-to-end data transfer, link access control, security, and providing support for real-time multimedia streaming [4]. No any requirement of centralized administration or fixed network infrastructure such as base stations or access points in ad hoc networks, and quickly and inexpensively set up can be done, as needed. A MANET consists of an autonomous group of mobile users that communicate over reasonably slow wireless links. Depending on the mobile nature of nodes, the network topology may vary rapidly and 
unpredictably over the time. The network is decentralized, where all the network activities, including discovering the topology and delivering messages must be executed by the nodes themselves.

MANET continuously maintain the information required to properly route the traffic. MANET is a type of wireless ad hoc network that usually has a routable networking environment on top of a Link Layer Ad hoc network. The growth of laptops and Wi-Fi wireless networking has made MANETs a popular research topic since the mid 1990s. Many academic papers analyze protocols and their abilities, in the basis of varying degrees of mobility within a bounded space.

\section{Routing Protocols}

Routing is a process of sending a message from one mobile node to another in the network (it is also called unicast).Routing protocols for mobile ad hoc wireless networks normally call for mobility management and scalable design. The mobility management is done by exchange the information between moving hosts in the ad hoc wireless network. Generally, when the frequent information exchanges occur, the network maintains accurate information of host locations and other relevant information. However, frequent information exchanges consume communication resources including bandwidth and power, so that it can be costly. With less frequent information exchanges, these costs decrese but there is more uncertainty about the location of host. Scalable design which works for large size networks requires both routing protocols and resource consumptions to be scalable. Routing in MANET poses special challenges because of its infrastructure-less network and its dynamic topology. Wired network uses traditional routing protocols, that generally use either link state or distance vector, but these protocols are not suitable for ad hoc wireless networks. In an environment, where mobile hosts work as routers, the network topology changes dynamically, hence the process could be expensive due to low bandwidth.

A routing protocol is required, whenever a packet needs to be communicate via several nodes to arrive at its destination. A routing protocol is necessary to find a route for packet delivery and make the packet delivered to the correct destination. Routing Protocols in Ad Hoc Networks can be classified into two types:

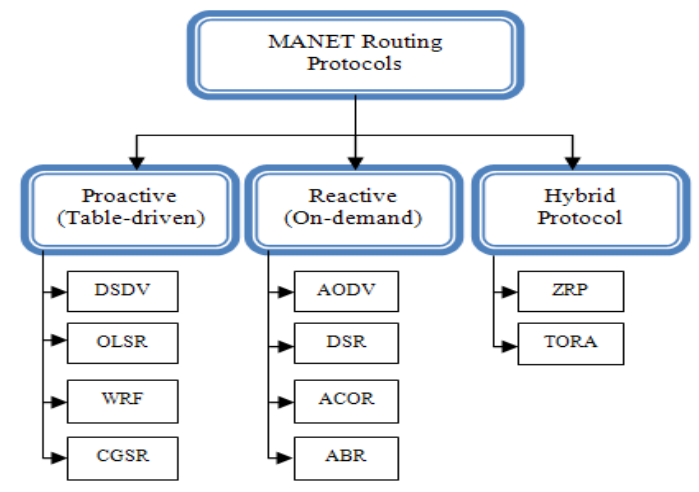

\section{A. Proactive or Table Driven Protocols}

Fig 2: Classification of Routing Protocols

Each node in the network contains routing table for broadcasting the data packets and want to establish Connection to other nodes in the network. These tables of nodes keep record for all the presented destinations, number of hops required to arrive at each destination in the routing table. A sequence number is used by the routing entry which is created by the destination node. Each station broadcasts and modifies its routing table from time to time, which specifies that how many hops are required to arrive that particular node and which stations are accessible. Each node that broadcasts data will contain its new sequence number.

Keeping routes to all destinations up-to-date, even if they are not used, is a disadvantage of proactive protocols regarding to the usage of bandwidth and of network resources.

Some of the famous table driven or proactive protocols are: DSDV,OLSR, GSR, WRP, ZRP, STAR etc.The proactive protocols are more appropriate for less number of nodes in networks, since the need to update the entries of node for each and every node in the routing table. Hence more routing overhead problems occur.

1) Dsdv

Destination Sequenced Distance Vector routing is a table driven routing scheme for MANET. This algorithm solve the routing loop problem. The routing table contains a sequence number for each entry. Generally, the sequence numbers are even if a link is present, else an odd number is used. The destination node generates the number and the emitter needs to send out the next update with this number. DSDV protocol should give the routes loop free paths. Extra traffic with incremental updates instead of full dump updates. Wastage of bandwidth due to unnecessary routing information even in store in table, no change in the network topology. DSDV doesn't support Multi path Routing. It is difficult to determine a time delay for the route.

2) Olsr 
The Optimized Link-State Routing protocol is proactive routing protocol or table driven protocol. Initially nodes contain routing tables and they update their routing tables time to time. It is based on the linkstate algorithm. Each node maintains the topology information of network and send this information from time to time to their neighbours. The unique quality of OLSR is that it minimizes the size of control messages and rebroadcasting by using the MRP (Multipoint Relaying). The basic concept of MPR is to reduce the loops of retransmissions of the packets. Only MPR nodes broadcast the route packets. The nodes within the network maintain a list of MPR nodes. MPR node is selected by the neighbor nodes in the network, with the help of HELLO messages.

\section{B. Reactive or On-demand Protocols}

Reactive routing protocol is also known as on demand routing protocol. In this protocol route is discovered whenever it is needed. Nodes initiate the discovery of route on demand basis. For the availability of route from source to destination, source node sees its route cache, if the route is not available then it initiates route discovery process. The two major components of on-demand routing protocols are route discovery and route maintance. This Protocol has lower overhead since routes are determined on demand. In ondemand concept, constant updation of route tables with the latest route topology is not required. Route discovery process is used in on demand routing by flooding the route request (RREQ) packets throughout the network. Examples of reactive routing protocols are the dynamic source Routing (DSR), ad hoc on-demand distance vector routing (AODV).

1) Dsr

The Dynamic Source Routing protocol is a simple and efficient routing protocol, which was designed specifically for use in multi-hop wireless ad hoc networks of mobile nodes. Without the need for any existing network infrastructure or administration, DSR allows the network to be completely self-organizing and self configuring. DSR uses source routing means that the source must know the complete hop sequence to the destination. A route cache is maintained by each node. Only if the desired route cannot be found in the route cache, the route discovery process is initiated. DSR uses source routing, the complete sequence of hops that each packet should be traverse is determined by the source. An advantage of DSR is that intermediate nodes can learn routes from the source routes in the packets they receive. Generally, finding a route is a costly operation in terms of time, bandwidth and energy, hence this is a strong argument for using source routing. The protocol uses two main mechanisms of Route Discovery and Route Maintenance, works together to allow nodes to discover and maintain routes to destinations in the ad hoc network.

\section{2) Aodv}

The Ad Hoc On-Demand Distance Vector routing protocol is a reactive protocol, when a source wants to initiate transmission with another node as destination in the network, AODV use control messages to find a route to the destination node in the network. It will provide topology information (like route) for the node. The node of network needs a connection broadcasts and request for connection. Other nodes forward this message, and record the node and creating an explosion of temporary routes back to the needy node. When a message received by a node and the node already has a route to the desired node, it sends a message backwards through a temporary route to the requesting node. The needy node then using the route that has the least number of hops through other nodes. Unused entries in the routing tables are recycled after a time. It uses route request and route reply messages.

\section{Hybrid Protocols}

Hybrid routing protocol have advantages of both proactive and reactive routing protocols. Firstly it behaves like proactive routing protocol, because starting nodes contains tables. Then whenever nodes finds that they doesn't have route to the destination, they start route discovery and behave like reactive routing protocols. Examples of hybrid protocols are TORA and ZRP.

1) Tora

Temporally Ordered Routing Algorithm is a hybrid protocol, based on a 'link reversal' algorithm. TORA discovers multiple routes to a destination, create routes quickly, and reduce communication overheads. Nodes have routing tables, so it helps the sending node to find the route to destination with the help of given tables. Routing tables also maintains the longer routes to avoid discovering newer routes. When a node finds that a route to a destination is no longer valid, it adjusts its height so that it is a local maximum with respect to its neighbors and transmits an UPDATE packet. If the node has no neighbors of finite height with respect to this destination, then the node discover a new route. When a node detects a network partition, it generates a CLEAR packet which resets routing tables and removes invalid routes which does not exist from the network. 


\section{2) $\operatorname{Zrp}$}

Zone Routing Protocol was the first hybrid routing protocol with both a proactive and a reactive routing component. ZRP was first introduced by Haas in 1997. It is proposed to reduce the control overhead of proactive routing protocols and decrease the latency caused by routing discover in reactive routing protocols. In ZRP, all nodes within hop distance from node belong to the routing zone of node. ZRP is formed by two subprotocols, a proactive routing protocol: Intra-zone Routing Protocol (IARP) is used $\mathrm{n}$ side routing zones and a reactive routing protocol: Inter-zone Routing Protocol (IERP), is used between routing zones, respectively.ZRP reduces the traffic amount compared to pure proactive or reactive routing. Routes to nodes within the zone are immediately available. ZRP is able to identify multiple routes to a destination, which provides increased reliability and performance. It ensures that the routes are free from loops.

\section{Performance Metrics}

MANET has number of qualitative and quantitative metrics that can be used to compare ad hoc routing protocols. This paper has been considered the following metrics to evaluate the performance of ad hoc network routing protocols.

1. End-to-end Delay:

This metric represents average end-to-end delay and indicates how long it took for a packet to travel from the source to the application layer of the destination. It includes all possible delay caused by buffering during route discovery latency, transmission delays at the MAC, queuing at interface queue, and propagation and transfer time. It is measured in seconds.

2. Packet Delivery Ratio:

Packet delivery ratio is calculated by dividing the number of packets received by the destination through the number of packets originated by the application layer of the source (i.e. CBR source). It specifies the packet loss rate, which limits the maximum throughput of the network.

3. Throughput:

It is the measure of the number of packets successfully transmitted to their final destination per unit time. It is the ratio between the number of received packets vs sent packets.

4. Packet Jitter:

It is the variation in the delay of received packets. At the sender they are evenly spaced intervals, but due to traffic congestion, improper queuing or configuration errors they come at unequal intervals.

5. Normalized Routing load:

It is defined as number of routing packets - transmitted, per data packet — delivered, at destination. Each hop-wise transmission of a routing is counted as one transmission. It is the sum of all control packet sent by all node in network to discover and maintain route.

IV. Simulation And Comparison Of Routing Protocols

A. Comparative Study Of Ad Hoc Routing Protocols

TABLE I. COMPARISON

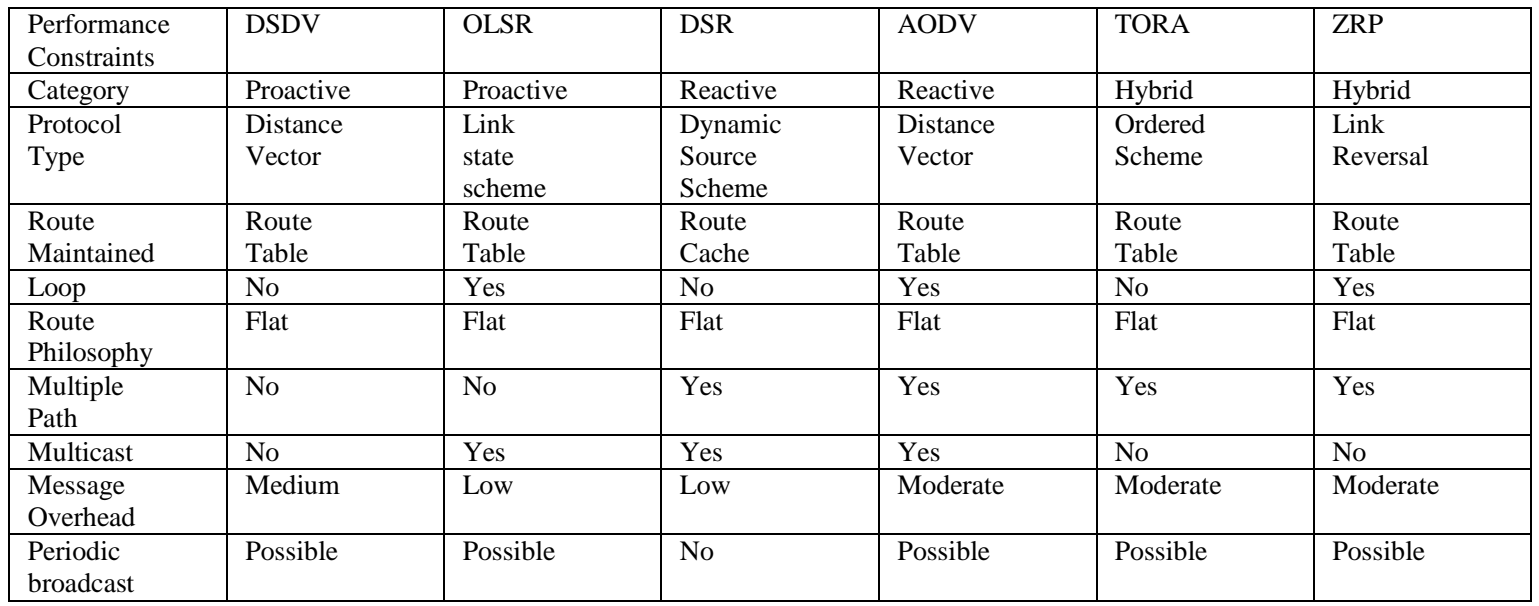




\begin{tabular}{|l|l|l|l|l|l|l|}
\hline $\begin{array}{l}\text { Requires } \\
\text { sequence }\end{array}$ & Yes & No & No & Yes & No & Yes \\
\hline
\end{tabular}

\section{B. Simulation Tool}

The tool used for simulation is NS-2 which is highly preferred by research communities. The network simulator version 2 (NS-2) is a package of tools that simulates behaviour of networks. It is a discrete event network simulator developed at UC Berkeley that focuses on the simulation of IP networks on the packet level. It can simulate both wired and wireless network. Wireless network research in the last years is often based on simulation. Ns-2 is a widely used wireless network simulation tool for this purpose.

$\mathrm{C}++$ and Tool Command Language (TCL) are the two languages used in NS-2. It uses TCL/OTCL (Tool Command Language/ Object Oriented TCL) as a command \& configuration interface. Basically TCL is its scripting and frontend language and $\mathrm{C}++$ is its backend language. NS-2 includes a tool for viewing the simulation results, called Network Animator (NAM). It uses three types of files namely Tool Command Language file (.tcl), Trace file (.tr) and Network Animator file (.nam). Tool command language file (.tcl) has subsets of commands which are written into it for simulation. While simulator runs on .tcl, simulation trace file (.tr) and animation file (.nam) are created during the session. Trace file (.tr) is used to trace the whole process and Network Animator file (.nam) is used to visualize the behaviour of network protocols and traffic the model.

\section{Performance Analysis Of Different Routing Protocols}

For comparing the performance of all the six protocols, two scenarios have been taken. First scenario is low mobility and low traffic and second scenario is high mobility and high traffic.

TABLE II. ROUTING PERFORMANCE IN LOW MOBILITY

\begin{tabular}{|c|c|c|c|c|c|}
\hline \multicolumn{6}{|c|}{ Low Mobility and Low Traffic } \\
\hline Protocol & $\begin{array}{l}\text { End to End } \\
\text { delay }\end{array}$ & $\begin{array}{l}\text { Packet } \\
\text { delivery } \\
\text { ratio }\end{array}$ & Throughput & $\begin{array}{l}\text { Packet } \\
\text { Jitter }\end{array}$ & $\begin{array}{l}\text { Routing } \\
\text { Overhead }\end{array}$ \\
\hline DSDV & $\begin{array}{l}\text { Least and } \\
\text { remains } \\
\text { constant as } \\
\text { the number } \\
\text { of nodes } \\
\text { increase in } \\
\text { the networks }\end{array}$ & High & $\begin{array}{l}\text { Least very } \\
\text { low when } \\
\text { compared } \\
\text { with DSR } \\
\text { and AODV }\end{array}$ & Low & High \\
\hline OLSR & Low & High & $\begin{array}{l}\text { High when } \\
\text { compared } \\
\text { with other } \\
\text { link state } \\
\text { protocols }\end{array}$ & Low & Average \\
\hline DSR & $\begin{array}{l}\text { Degrade when } \\
\text { number of } \\
\text { nodes increase in } \\
\text { the networks }\end{array}$ & High & $\begin{array}{l}\text { At speed } \\
30 \mathrm{~m} / \mathrm{s} \\
\text { throughput } \\
\text { increases } \\
\text { better than } \\
\text { DSDV } \\
\end{array}$ & $\begin{array}{l}\text { Very } \\
\text { High }\end{array}$ & $\begin{array}{l}\text { Increases with } \\
\text { an increase in } \\
\text { the number of } \\
\text { nodes }\end{array}$ \\
\hline AODV & $\begin{array}{l}\text { Performance } \\
\text { Degrade } \\
\text { with number } \\
\text { of nodes } \\
\text { increase in } \\
\text { the networks }\end{array}$ & High & Best & High & $\begin{array}{l}\text { Increases } \\
\text { proportionally } \\
\text { with an } \\
\text { increase in the } \\
\text { number of } \\
\text { nodes }\end{array}$ \\
\hline TORA & Low & High & Low & Medium & Medium \\
\hline$\overline{Z R P}$ & Low & High & Average & Low & Low \\
\hline
\end{tabular}

TABLE III. ROUTING PERFORMANCE IN HIGH MOBILITY

\begin{tabular}{|l|l|l|l|l|l|}
\hline \multicolumn{5}{|c|}{ High Mobility and High Traffic } \\
\hline Protocol & $\begin{array}{l}\text { End to } \\
\text { End } \\
\text { delay }\end{array}$ & $\begin{array}{l}\text { Packet } \\
\text { delivery } \\
\text { ratio }\end{array}$ & Throughput & $\begin{array}{l}\text { Packet } \\
\text { Jitter }\end{array}$ & $\begin{array}{l}\text { Routing } \\
\text { Overhead }\end{array}$ \\
\hline DSDV & High & High & Low & $\begin{array}{l}\text { Very high for a } \\
\text { Slight increase } \\
\text { in the number } \\
\text { of nodes }\end{array}$ \\
\hline OLSR & Low & Average & Good & Low & $\begin{array}{l}\text { Increases with an } \\
\text { increase in the } \\
\text { nodes }\end{array}$ \\
\hline DSR & High & Low & Average & High & $\begin{array}{l}\text { Increases with an } \\
\text { Increase in the } \\
\text { Number of nodes }\end{array}$ \\
\hline
\end{tabular}




\begin{tabular}{|l|l|l|l|l|l|}
\hline AODV & Average & Average & Average & High & Low \\
\hline TORA & High & Low & Low & Average & Average \\
\hline ZRP & High & Low & Average & Average & Low \\
\hline
\end{tabular}

\section{Conclusion}

This paper presents the comparative study and performance analysis of various ad hoc routing protocols (DSDV, OLSR, DSR, AODV, TORA and ZRP) on the basis of end-to-end delay, packet delivery ratio, throughput, routing overhead, jitter performance metrics. By observing the table II and III, it is found that AODV has maximum throughput under low traffic and DSDV has maximum throughput under high traffic. As network becomes dense OLSR, DSR and DSDV perform well in terms of Throughput than AODV and TORA. TORA performs well in dense networks in terms of packet delivery fraction but at the same time Normalized Routing load of TORA is maximum among all the protocols in both the networks. Most evaluations and comparisons of protocols for ad-hoc networks skip ZRP. The reason is usually that ZRP is aimed for larger networks than the test comprises, or that ZRP is not an independent protocol but rather a routing framework. Further, any evaluation of the ZRP version with support for unidirectional links could not be found. It is especially well adapted to large networks and diverse mobility patterns. DSDV has least Normalized Routing load in both low and high traffic. OLSR and DSDV give the least Jitter and Average Delay in both networks Low delay and low jitter are mainly required in voice applications and real time applications, so OLSR and DSDV can be used there. The applications like voice and video conferencing need more BW, so in this case DSDV can be used. The applications like video telephony, web games, etc. require high throughput, so in this case AODV can be used under low mobility and low traffic and DSDV can be used under high mobility and high traffic. There is high mobility of users and network nodes at the time of emergency and military operations. We have observed that as the mobility increases there is an improvement in the throughput of OLSR, DSR and DSDV. So these three protocols can be used in emergency and military applications.

\section{References}

[1] Zehua Wang, Yuanzhu Chen and Cheng Li, - PSR: A Lightweight Proactive Source Routing Protocol For Mobile Ad Hoc Networksl,IEEE Transactions on Vehicular Technology, Vol. 63, no. 2, February 2014.

[2] Seema Vilas Bhujade, Prof. S. D. Sawant, -Evaluation AODV, DSR and DSDV Protocol of MANET by USING NS-2\|, IJET, Volume 4 Issue 8- August 2013.

[3] D GEETHA, T SARIKA, -Performance Analysis of TORA \& DSR Routing Protocols in Mobile Ad-hoc Networksll, IJECSE, Volume 2,Number 1.

[4] Basu Dev Shivahare, Charu Wahi, Shalini Shivhare, - Comparison Of Proactive And Reactive Routing Protocols In Mobile Adhoc Network Using Routing Protocol Propertyll, International Journal of Emerging Technology and Advanced Engineering, Volume 2, Issue 3, March 2012.

[5] Zehua Wang, Yuanzhu Chen, Cheng Li, _CORMAN: A Novel Cooperative Opportunistic Routing Scheme in Mobile Ad Hoc Networksl, IEEE JOURNAL ON SELECTED AREAS IN COMMUNICATIONS, VOL. 30, NO. 2, FEBRUARY 2012.

[6] D. Johnson, Y. Hu, D. Maltz, - The Dynamic Source Routing Protocol (DSR) for Mobile Ad Hoc Networks for IPv4ll, Microsoft Research,February 2007.

[7] Zehua Wang, Cheng Li, and Yuanzhu Chen, _PSR: Proactive Source Routing in Mobile Ad Hoc Networksll, IEEE GLOBECOM 2011.

[8] Prakash B. Khelage, Dr. Uttam Kolekar, - Survey and Simulation base Performance Analysis of TCP-Variants in terms of Throughput, Delay and drop Packets over MANETsll, International Journal of Scientific \& Engineering Research, Volume 5, Issue 1, January 2014.

[9] T. Clausen, P. Jacquet, —Optimized Link State Routing Protocol (OLSR) \|, INRIA, October 2003.

[10] Charles E. Perkins, Elizabeth M. Royer, - Ad-hoc On-Demand Distance Vector Routingl.

[11] Suresh Kumar, Jogendra Kumar, -Comparative Performance Analysis of Routing Protocols in MANET using Varying Pause Timell, International Journal of Computer Applications Volume 47- No.12, June 2012. 